\title{
COLOUR DOPPLER CHANGES IN IUGR WITH RESPECT TO PULSATILITY INDEX OF UA AND MCA AND CEREBROPLACENTAL RATIO
}

\section{Dr. Ayushi Agarwal* \\ Dr. Sanjaya Sharma}

Junior Resident, Department Of Obstetrics \& Gynaecology, MLB Medical College, Jhansi, UP *Corresponding Author

Professor \& Head, Department Of Obstetrics \& Gynaecology, MLB Medical College, Jhansi, UP

Assistant Professor, Department Of Obstetrics \& Gynaecology, MLB Medical College, Jhansi, UP

\section{ABSTRACT BACKGROUND : Doppler indices form an integral component of noninvasive evaluation of fetal well-} being. There is paucity of information about normal obstetric Doppler indices, particularly from the Indian subcontinent. The aim of the study was to find the values of pulsatility index (PI), resistive index (RI) of umbilical artery (UA), and fetal middle cerebral artery (MCA) and calculate cerebro-placental ratio (CP ratio) for 31-41 weeks of normal gestation.

METHODS : 250 patients were enrolled in the study for color Doppler study of UA and MCA and were serially followed up at 4-6 weeks interval for Doppler indices. Angle-independent Doppler indices like PI and RI for MCA and UA were obtained during each examination. CP ratio was calculated in each case. All the cases were followed up till delivery and the perinatal outcome was recorded.

RESULTS \& CONCLUSION : Abnormal cerebroplacental ratio is strongly correlated with IUGR and worse fetal prognosis. Fetuses with abnormal doppler velocimetry have a significantly higher incidence of preterm birth, low birth weight and admission to NICU.Associated risk factors were anemia, PIH, DM, previous history of IUGR, TORCH infection, thyroid disorder. Anemia was found to be common risk factor followed by PIH. In conclusion with the help of non-invasive color Doppler parameters we can identify those pregnancies which are at risk and intervene before the fetus actually become growth restricted and act accordingly for better perinatal outcome.

\section{KFYWORDS : Doppler Indices, Middle Cerebral Artery, Umbilical Artery, Cerebroplacental Ratio}

\section{INTRODUCTION}

Intra uterine growth retardation (IUGR) is defined as the failure to achieve specific fetal biometric measures or estimated weight (<10th percentile) by a specific gestational age due to some pathologic process that inhibits expression of the normal intrinsic growth potential. IUGR is associated with increased fetal and neonatal morbidity and mortality.

Doppler investigation is an efficient method of surveillance in IUGR monitoring ${ }^{(1)}$. Hemodynamic changes involve maternal uterine, fetal umbilical (UA), middle cerebral (MCA), umbilical vein (UV) and ductus venosus (DV) ${ }^{(2,3)}$.

The circulation in Umbilical artery (UA) is normally a lowimpedance circulation, with an increase in the amount of enddiastolic flow with advancing gestation ${ }^{(4,5)}$.

Umbilical arterial Doppler waveforms reflect the status of the placental circulation, and the increase in end-diastolic flow that is seen with advancing gestation is a direct result of an increase in the number of tertiary stem villi that takes place with placental maturation ${ }^{(6,7)}$.

In 2013, the International Society for Ultrasound in Obstetrics and gynecology (ISUOG) recommended taking Doppler measurements from a free loop cord for the sake of simplicity and consistency ${ }^{(8)}$.

Middle cerebral artery (MCA) is the vessel of choice to assess the fetal cerebral circulation because it is easy to identify, is highly reproducible and it carries more than $80 \%$ of cerebral blood flow ${ }^{(9)}$. In the presence of fetal hypoxemia, central redistribution of blood flow occurs, resulting in increased blood flow to the brain, heart, and adrenals and a reduction in flow to the peripheral and placental circulations. This blood flow redistribution is known as the brain-sparing effect and plays a major role in fetal adaptation to oxygen depr I vation $^{(10,11)}$.

Here, the purpose of the study is to find out the role of color Dop pler ultrasonography in association with IUGR.

\section{MATERIAL AND METHODS}

The observational prospective study was conducted in Department of Obstetrics and Gynaecology, MLB Medical College Jhansi from March 2018 to August 2019.

The study was conducted among 250 cases of pregnant women in 31-4lweeks of gestation with clinically suspected IUGR. All pregnant women underwent Doppler Velocimetry of umbilical and middle cerebral arteries in coordination with the department of Radio Diagnosis and Imaging.

Full term pregnant women with following criteria were included in the study:

1. Well known last menstrual period.

2. Singleton pregnancy

3. Clinically suspected of IUGR (based on findings such as insufficient weight gain, decrease or no increase in abdominal girth and decrease or no increase in fundal height.)

4. Known cases of pregnancy induced hypertension, gestational hypertension, preeclampsia, eclampsia

5. Known cases of diabetes mellitus, history of TORCH infection.

6. Previous history of IUGR.

7. Based on obstetric grey scale ultrasound FL/AC, HC/AC ratio.

The cases with following criteria were excluded from the study:

i. Wrong dates/LMP not sure

ii. Fetus with congenital anomaly

iii. Not willing to participate

iv. Twin pregnancy 
Abnormal Perinatal Outcome was noted as IUGR - birth weight $<10$ percentile for the gestational age. And any of the following -

Thick MSL

NICU admission within $72 \mathrm{hrs}$

Apgar score $<7$ at 5 min

Perinatal death

\section{STATISTICAL ANALYSIS}

All information collected from the patients were entered in the computer using Microsoft excel. All quantitative data were presented in form of mean and standard deviation. Sensitivity and specificity of the test was calculated. Chi square test applied to calculate statistical association between two qualitative variables. $p$ value $<0.05$ was considered as statistical significance at $95 \%$ confidence interval.

\section{RESULTS}

This study was conducted among 250 high risk mothers to study Doppler flow in umbilical artery and middle cerebral arteries. Women in reproductive age group 21-25 yrs present with maximum $45.6 \%$ of clinically suspected cases of IUGR followed by age group of $26-30$ yrs (31.2\%). Most of the women $60.4 \%$ belong to rural cases as compared to $39.6 \%$ of urban areas.

$57.6 \%$ of clinically suspected cases of IUGR are primigravida whereas $41.4 \%$ are multigravida. Majority of patients of clinically suspected cases of IUGR belong to gestational age $35-37$ wks accounting to $32.8 \%$, followed by gestational age $33.1-35$ wks accounting to $28.0 \%$.

Table 4: UA and MCA and PI and CPR as predictors of IUGR

\begin{tabular}{|c|c|c|c|c|c|c|}
\hline \multicolumn{2}{|c|}{ Artery doppler } & \multirow{2}{*}{$\begin{array}{c}\begin{array}{c}\text { Cases with } \\
\text { IUGR }\end{array} \\
88 \\
\end{array}$} & \multirow{2}{*}{$\begin{array}{c}\text { Cases without } \\
\text { IUGR } \\
104\end{array}$} & \multirow{3}{*}{$\begin{array}{c}\text { Sensitivity } \\
37 \%\end{array}$} & \multirow{3}{*}{\begin{tabular}{|c|} 
Specificity \\
$77.6 \%$
\end{tabular}} & \multirow{3}{*}{$\begin{array}{l}\mathrm{P} \text { value } \\
\mathrm{p}<0.05\end{array}$} \\
\hline \multirow[t]{2}{*}{ UA PI } & Normal & & & & & \\
\hline & Ábnormal & 40 & 30 & & & \\
\hline \multirow[t]{2}{*}{ MCA PI } & Normal & 74 & 124 & \multirow[t]{2}{*}{$22.9 \%$} & \multirow[t]{2}{*}{$80.5 \%$} & \\
\hline & Äbnormal & 22 & 30 & & & \\
\hline \multirow[t]{2}{*}{ CPR } & Normal & 34 & 146 & \multirow[t]{2}{*}{$61.7 \%$} & \multirow[t]{2}{*}{$90.68 \%$} & \multirow[t]{2}{*}{$\mathrm{P}<0.05$} \\
\hline & Ábnormal & 55 & 15 & & & \\
\hline
\end{tabular}

Table 5 : UA and MCA and PI and CPR as predictors of IUGR

\begin{tabular}{|l|l|l|l|l|l|}
\hline $\begin{array}{l}\text { Artery } \\
\text { doppler }\end{array}$ & Thick MSL & $\begin{array}{l}\text { Apgar score at } \\
<7 \text { min }\end{array}$ & $\begin{array}{l}\text { NICU } \\
\text { admission }\end{array}$ & \multicolumn{2}{|l|}{$\begin{array}{l}\text { Perinatal } \\
\text { death }\end{array}$} \\
\hline \multirow{4}{*}{ UA } & S/D ratio & 42 & 54 & 64 & 1 \\
\cline { 2 - 7 } & PI & 55 & 58 & 50 & 2 \\
\cline { 2 - 7 } & RI & 22 & 28 & 30 & 0 \\
\hline \multirow{4}{*}{ MCA } & S/D ratio & 35 & 20 & 42 & 1 \\
\cline { 2 - 7 } & PI & 42 & 18 & 38 & 1 \\
\cline { 2 - 6 } & RI & 24 & 22 & 25 & 0 \\
\hline CPR & PI & 54 & 62 & 72 & 5 \\
\hline
\end{tabular}

Adverse perinatal outcome in terms of fluid MSL low APGAR score, NICU admission, perinatal death were more with abnormal CPR.

Table 6: Distribution according to causes

\begin{tabular}{|l|l|l|}
\hline Causes & No. of cases & Percentage \\
\hline Hypertension & 120 & 48.0 \\
\hline Anaemia & 154 & 61.60 \\
\hline Diabetes mellitus & 7 & 2.8 \\
\hline TORCH infection & 2 & 0.8 \\
\hline Previous history of IUGR & 3 & 1.2 \\
\hline Hypothyroidism & 2 & 0.8 \\
\hline Others & 10 & 4.0 \\
\hline Total & 250 & $100 \%$ \\
\hline
\end{tabular}

Andemia is the most common cause found in $61.60 \%$ of cases followed by hypertension which accounts in $48.0 \%$ of cases.
Table 1: Normal and Abnormal Doppler variables for UA

\begin{tabular}{|c|c|c|c|c|}
\hline \multirow{2}{*}{ Doppler variables } & \multicolumn{4}{|c|}{ UA } \\
\cline { 2 - 5 } & Normal & $\%$ & Abnormal & $\%$ \\
\hline S/D ratio & 184 & 73.6 & 66 & 26.4 \\
\hline Pulsatility Index & 170 & 68.0 & 70 & 28.0 \\
\hline Resistance Index & 168 & 67.2 & 82 & 32.8 \\
\hline
\end{tabular}

Above table shows various abnormal and normal Doppler variables of Umbilical Artery. For Umbilical Artery abnormal $\mathrm{S} / \mathrm{D}$ ratio was found in 66 cases $(26.4 \%)$, abnormal Pulsatility Index was found in 70 (28.0\%) and abnormal Resistance Index was found in 82 (32.8\%).

Table 2: Normal and Abnormal Doppler variables for MCA

\begin{tabular}{|c|c|c|c|c|}
\hline \multirow{2}{*}{ Doppler variables } & \multicolumn{4}{|c|}{ MCA } \\
\cline { 2 - 5 } & Normal & $\%$ & Abnormal & $\%$ \\
\hline S/D ratio & 170 & 68.0 & 80 & 32.0 \\
\hline PI & 198 & 79.2 & 52 & 20.8 \\
\hline RI & 182 & 72.8 & 68 & 27.2 \\
\hline
\end{tabular}

Above table shows various abnormal and normal Doppler variables of MCA. Abnormal S/D ratio was found in 80 (32.0\%) cases, abnormal pulsatility index was found in $52(20.8 \%)$ cases and abnormal resistance index was found in 68 (27.2\%) cases.

Table 3: Normal and Abnormal Doppler variables for CPR

\begin{tabular}{|c|c|c|c|c|}
\hline \multirow{2}{*}{ Doppler variables } & \multicolumn{4}{|c|}{ CPR } \\
\cline { 2 - 5 } & Normal & $\%$ & Abnormal & $\%$ \\
\hline Pulsatility Index & 180 & 72.0 & 70 & 28.0 \\
\hline
\end{tabular}

Above table shows various abnormal and normal Doppler variables of CPR. Abnormal Pulsatility Index was found in 70 (28.05\%).

\section{DISCUSSION}

In the present study out of 250 women with suspected IUGR, 99 women $(39.61 \%)$ were form urban area and 151 women $(60.4 \%)$ from rural area. Further shows maximum cases 114 $(45.6 \%)$ in the age group $21-25$ years followed by age group $26-30$ years $(31.2 \%)$.

Women below the age group 20 years and 30 years constituted only $13.6 \%$ and $9.6 \%$. This is in concordance with the study of Mallik and Saxena (2013) ${ }^{(12)}$. They found increased risk of IUGR in 21-25 years of age group (47\%). The mean age group was 25.5 years in the study by Sharma and Bhatnagar $(2010)^{(13)}$.

In the present study out of 250 mothers 144 (57.6\%) mothers were primary gravid whereas $106(42.4 \%)$ were multigravida. Sumangali et al, 2017 reported 52\% multiparous and $48 \%$ primary and multiparous in their study. Our study commensurate with Wen et al, 1990 ${ }^{(14)}$ who found IUGR more common in primary gravid. Malik and Saxena, 2013 $3^{(12)}$ reported 49\% primary gravid in 2013.

\section{UMBILICAL ARTERY EVALUATION}

In this study abnormal S/D ratio was present in $26.4 \%$ cases, abnormal pulsatility index in $28 \%$ cases and abnormal resistance index in $32.8 \%$. The sensitivity of umbilical artery PI was $37 \%$ whereas specificity was $77.6 \%$. A study conducted by Gramellini et al (1992) ${ }^{(15)}$ reported 64\% sensitivity for PI and a specificity of $70.02 \%$ which is concordance with present study. 
It also correspond to Fong et al ${ }^{(16)}$ where sensitivity was $44.7 \%$ and specificity was $86.6 \%$. In a study by Sharma and Bhatnagar (2010) ${ }^{(13)} \mathrm{S} / \mathrm{D}$ ratio pulsatility index and resistance index of the umbilical artery is significantly higher in the high risk pregnant women $(\mathrm{P}<0.001)$.

\section{MIDDLE CEREBRAL ARTERY}

In the present study abnormal S/D ratio was $32 \%$, found in abnormal PI ratio in $20.8 \%$ and abnormal resistance index in $27.2 \%$, patients sensitivity for MCA PI was $22.9 \%$ whereas specificity was $80.5 \%$. The study is in concordance with the study by Gramellini et al (1992) ${ }^{(15)}$ in which sensitivity was $24 \%$ and specificity was $100 \%$. Similar findings with sensitivity $41.6 \%$ and specificity of $99.9 \%$ was also mentioned in Lakhar et al $(2006)^{(17)}$ whereas Fong I $(1999)^{(16)}$ reported sensitivity of $72.4 \%$ and specific $58.1 \%$ which do not correlate with our study.

\section{CEREBROPLACENTAL RATIO}

In the present study sensitivity of cerebroplacental ratio (CPR) is $61.7 \%$ and specificity $90.6 \%$. This corresponds with the study of Gramelline et al (1992) ${ }^{(15)}$ where sensitivity was $68 \%$ and specificity $98.4 \%$. Lakhor et al $(2006)^{(17)}$ reported sensitivity of $47.2 \%$ and specificity of $86.3 \%$. In another study by Fong et al $(1999)^{(16)}$ sensitivity was $51.3 \%$ and specificity $80.6 \%$. All justify the present study. Gramelline et al (1992) ${ }^{(15)}$ highlighted that CPR provide a better diagnostic accuracy than either vessel (RI) considered alone.

The study also evaluated the perinatal outcome in terms of birth weight, APGAR score and NICU admission and found correlation with SD ratio and RI and PI of UA and MCA. A study by Arduini and Rizzo, $1992^{(18)}$ is an observational cross sectional study of 4 fetal vessel, there was combination of middle cerebral and umbilical artery Doppler velocimetry indices to produce ratio that gave the best method of predicting perinatal outcome. They finally concluded that these ratios of predicted hemodynamic changes in fetus are better than single vessel Doppler indices.

In this study among those women where the cause of IUGR was identified, $61.61 \%$ had anaemia, $48 \%$ has pregnancy induced hypertension complicating pregnancy. In a study by Devoe and Ramossantos, $1993^{(19)}$, the association between PIH and IUGR was demonstrated and anemia was found to be most commonly associated.

\section{CONCLUSION}

Women in reproductive age group of 21-25 years and primi gravid comprises maximum no. of cases in our study. Abnormal cerebroplacental ratio is strongly correlated with IUGR and worse fetal prognosis. UA PI is more sensitive parameter as compared to MCA PI whereas both are almost equally specific. Fetuses with abnormal doppler velocimetry have a significantly higher incidence of low birth weight and admission to NICU and perinatal morbidity and mortality. Associated risk factors were anemia, PIH, DM, previous history of IUGR, TORCH infection, thyroid disorder, PIH was found to be the most common risk factor. Significant association of IUGR with oligohydramnios was present.

We conclude that with the help of non-invasive color Doppler parameters we can identify those pregnancies which are at risk and intervene before the fetus actually become growth restricted and act accordingly for better perinatal outcome.

\section{REFERENCES}

1. M. Y. Divon, "Umbilical artery Doppler velocimetry: clinical utility in high risk pregnancies,"American Journal of Obstetrics and Gynecology, vol. 174, no. 1, pp. 10—14, 1996.

2. O. M. Turan, S. Turan, S. Gungor et al., "Progression of Doppler abnormalities in intrauterine growth restriction,"Ultrasound in Obstetrics and Gynecology, vol. 32, no. 2, pp. 160-167, 2008.

3. G. Rizzo, A. Capponi, 0. Cavicchionp, M. Vendola, and D. Arduini, "Low cardiac output to the placenta: an early hemodynamic adaptive mechanism in intrauterine growth restriction," Ultrasound in Obstetrics \& Gynecology, vol. 32, no. 2,pp. 155-159, 2008.

4. Fleischer A, Schulman H, Farmakides G, et al: Umbilical artery waveforms and intrauterine growth retardation. Am J Obstet Gynecol 151:502, 1985

5. Ott WJ: The diagnosis of altered fetal growth. Obstet Gynecol Clin North Am 15:237, 1988.

6. Giles WB, Trudinger BJ, Baird PJ: Fetal umbilical artery flow velocity waveforms and placental resistance: pathological correlation. Br J Obstet Gynecol 92:3 1, 1985

7. Manning FA: Intrauterine growth restriction. Diagnosis, prognostication, and management based on ultrasound methods. In Manning FA, editor: Fetal Medicine: Principles and Practice, Norwalk, CT, 1995, Appleton \& Lange, pp 8 7-94.

8. Bhide A, Acharya G, Bilardo CM, et al: ISUOG practice guidelines: use of Doppler ultrasonography in obstetrics. Ultrasound Obstet Gynecol 41(2):233-239, 2013

9. Veille JC, Hanson R, Tatum K: Longitudinal quantitation of middle cerebral artery blood flow in normal human fetuses. Am J Obstet Gynecol 169:1393, 1993.

10. Mari G, Deter RL: Middle cerebral artery flow velocity waveforms in norma and small-for-gestational age fetuses. Am J Obstet Gynecol 166:1262, 1992.

11. Soothill PW, Ajayi RA, Campbell S, et al: Relationship between fetal academia at cordocentesis and subsequent neurodevelopment. Ultrasound Obstet Gynecol 2:80, 1992.

12. Rajesh Malik, Agamya Saxena. Role of Colour Doppler Indices in the Diagnosis of Intrauterine Growth Retardation in High-Risk Pregnancies. J Obstet Gynaecol India. 2013 Mar; 63(1): 37-44

13. Sharma U, Bhatnagar B. Triple vessel wave pattern by Doppler studies in normal and high risk pregnancies and perinatal outcome. J Obstet Gynecol India 2010;60(4):312-316.

14. Wen, S.W., Goldenberg, R.L. Cutter, G.R., Hoffman, H.J. \& Cliver, S.P Intrauterine growth retardation and preterm delivery, prenatal risk factors in an indigent population. American Journal of Obstetrics \& Gynaecology, Vol 162, pp. 213-218

15. Gramelline D, Folli MC, Raboni S, Vadora E, Merialdi A. Cerebral umbilical Doppler ratio as a predictor of adverse perinatal outcome. Obstet Gynecol, 1992 Mar; 79(3) : 416-20.

16. Fong KW, Ohlsson A, Hanah Me, Kingdom J. Prediction of Perinatal Outcome in Foetuses Suspected to Have Intrauterine Growth Restriction. Doppler US Study of Foetal Cerebral, Renal, and Umbilical Arteries - Radiology. 1999;213:681-9

17. Lakhkar BN, Rajagopal KV, Gourisankar PT. Doppler Prediction of Adverse Perinatal Outcome in PIH and IUGR. IJRI. 2006;16:1:109-16.

18. Rizzo Gl, Arduini D, Luciano R, Rizzo C, Tortorolo G, Romanini C, Mancuso S. Prenatal cerebral Doppler ultrasonography and neonatal neurologic outcome. J Ultrasound Med. 1989 May;8(5):237-40.

19. Devoe LDl, Ramos-Santos E. Antepartum fetal assessment in hypertensive pregnancies. Clin Perinatol. 1991 Dec;18(4):809-32. 